Uitterhoeve, R., Bensing, J., Grol, R., deMulder, P., Achterberg, T. van. The effect of communication skills 7 training on patient outcomes in cancer care: a systemtatic review of the literature. European Journal oftean Care: 2010, 19 (4), 442-457.

\begin{tabular}{|l|l|}
\hline $\begin{array}{l}\text { Postprint } \\
\text { Version }\end{array}$ & 1.0 \\
\hline Journal website & $\underline{\mathrm{http}: / / \mathrm{www} 3 . \text { interscience.wiley.com/journal/123216548/abstract }}$ \\
\hline Pubmed link & $\underline{\mathrm{http} / / / \mathrm{www} \text {.ncbi.nlm.nih.gov/pubmed/20030702 }}$ \\
\hline DOI & $10.1111 / \mathrm{j} .1365-2354.2009 .01082 . \mathrm{x}$ \\
\hline
\end{tabular}

This is a NIVEL certified Post Print, more info at http://www.nivel.eu

\title{
The effect of communication skills training on patient outcomes in cancer care: a systematic review of the literature
}

\author{
R.J. UITTERHOEVE, RN, PHD ${ }^{1}$, J.M. BENSING, PHD, PROFESSOR ${ }^{2}$, R.P. GROL, PHD, PROFESSOR ${ }^{3}$, \\ P.H.M. DEMULDER (DECEASED), PHD, MD, PROFESSOR ${ }^{4}$, \& T. VAN ACHTERBERG, RN, PHD, \\ PROFESSOR $^{3}$ \\ ${ }^{1}$ Scientific Institute for Quality of Healthcare, IQ Healthcare 114, Radboud University Nijmegen Medical \\ Centre, PO Box 9101, 6500 HB Nijmegen \\ ${ }_{2}$ Netherlands Institute for Health Services Research, Research Institute for Psychology and Health, \\ Utrecht \\ ${ }^{3}$ Scientific Institute for Quality of Healthcare, IQ Healthcare 114, Radboud University Nijmegen \\ Medical Centre, Nijmegen, The Netherlands \\ ${ }^{4}$ Radboud University Nijmegen Medical Centre, Department of Medical Oncology, Nijmegen \\ Correspondence to Ruud J. Uitterhoeve, Scientific Institute for Quality of Healthcare, IQ Healthcare 114, \\ Radboud University Nijmegen Medical Centre, PO Box 9101, 6500 HB Nijmegen, The Netherlands (e- \\ mail: r.uitterhoeve@cis.umcn.nl).
}

\begin{abstract}
The objective of this review was to determine whether communication training for healthcare professionals (HCP), including nurses and medical doctors, in cancer care improves patient outcomes. Eligible studies with a focus on patient outcomes and a controlled or single group pretest-posttest design were identified according to Cochrane Collaboration Guidelines. Seven studies, encompassing 10 papers and involving five randomised controlled trials, were included. Studies involved $411 \mathrm{HCP}$, including a total of 1677 encounters with adult cancer patients. Forty-nine papers were excluded, primarily because no patient outcomes were reported. Regarding patient satisfaction outcomes, estimated effects in favour of communication training ranged from 0.07 (95\% CI: -0.30 to 0.44) for satisfaction with information and support to 0.70 (95\% CI: 0.16 to 1.24 ) for satisfaction with assessment of concerns. No evidence was found for the effectiveness of communication training on patient distress outcomes. We concluded that the current review reveals inconclusive evidence to prove the effectiveness of communication training on patient satisfaction and patient distress. More high-quality studies are needed.
\end{abstract}

There is much agreement on the importance of effective communication in cancer care. It has been demonstrated that effective communication can reduce stress, feelings of anxiety and uncertainty in patients. Conversely, ineffective communication can have adverse effects on patient compliance and can leave patients feeling anxious, uncertain and generally dissatisfied with their care (Maguire et al. 1996a; Butow et al. 2002a). Yet, it is frequently observed that the quality of communication with patients is insufficient. In a recent descriptive study (Uitterhoeve et al. 2003), which aimed to identify problem areas in the care for patients receiving chemotherapy, professional caregivers (medical oncologists and 
Uitterhoeve, R., Bensing, J., Grol, R., deMulder, P., Achterberg, T. van. The effect of communication skills training on patient outcomes in cancer care: a systemtatic review of the literature. European Journal of Canc $^{\circ}$ Care: 2009

oncology nurses) and patients alike reported that affective communication in particular is in need of improvement. Patients expressed the opinion that the level of discussion of psychosocial aspects of their disease is far from adequate. In addition, professional caregivers acknowledged that this specific area of communication should be improved. This is supported by other findings, indicating that nurses overlook patients' social and emotional needs and focus on physical care instead. It has been observed that only $40-55 \%$ of existing patient concerns are adequately identified, which are predominantly concerns related to physical symptoms (Heaven \& Maguire 1997; Heaven 2001; Hill et al. 2003; Farrell et al. 2005). Nurses often use blocking behaviour (ranging from $55 \%$ to $75 \%$ of the occasions), thus avoiding subjects that are emotionally charged, rather than stimulating patients to express their concern (Wilkinson 1991; Dennison 1995; Ford et al. 1996; Maguire et al. 1996b; Suchman et al. 1997; Andersen \& Adamsen 2001). Other studies (Bensing 1991; Ong et al. 2000) suggest that it is especially important to improve the emotional dimension of provider-patient communication, as patient outcomes, i.e. satisfaction with care and quality of life, are most affected by the emotional dimension of communication.

In recent years, there has been a greater emphasis on communication skills training for healthcare professionals (HCP) who care for patients with cancer. Reviews of the literature (Kruijver et al. 2000; Fellowes et al. 2004; Gysels et al. 2004) demonstrate that HCP can be trained to communicate more effectively with patients who have cancer. Currently, questions remain as to whether improvement of HCP communication has a beneficial effect on patient outcomes. Patient-rated emotional measures and patient satisfaction are recognised to be important endpoints of studies evaluating health care. These measures will also be used as primary outcome measures for this review. A secondary outcome of this is the actual performance of HCP communicative behaviour in real patient encounters. This review aims to evaluate the effectiveness of communication skills training programmes for HCP working in cancer care on patient outcomes.

\section{METHODS}

\section{Search strategy and selection criteria}

First, computerised databases of Medline (1989-2007), PsycInfo (1989-2007) and Cinahl (1982-2007) were searched using the following procedure. Subject-specific keywords used to describe the evaluation of training programmes to improve communication of HCP in oncology were selected by using the thesaurus function of the databases. The selected subject-specific keywords for HCP in oncology and communication training were separately combined (using the Boolean operator 'OR') with relevant free text words. The two searches were then combined (using the Boolean operator 'AND'). The search was then combined (using the Boolean operator 'AND') with a database-specific methodological filter limiting the search to controlled studies and studies with a single group pretest-posttest design. The search was then limited to papers published between 1990 and 2007 (Table 1).

Second, references of all relevant papers were checked to identify additional papers. Third, to identify additional relevant studies, the Science Citation Index was used to search for studies that have cited located, relevant papers. Fourth, leaders in the field were contacted to locate relevant but currently unpublished studies or suggest others who possibly know of unpublished work.

Retrieved studies were independently assessed for inclusion by two reviewers (R.U. and T.v.A.) and included if all of the inclusion criteria were met. Inclusion and exclusion criteria are summarised in Table 2. Disagreement over inclusion between the reviewers was resolved through discussion.

\section{[TABLE 1] AND [TABLE 2]}

\section{Data extraction}

Data were extracted from eligible papers and included: the sample (inclusion/exclusion criteria, patients' socio-demographic data and the socio-professional data of HCP), the setting (inpatient, outpatient, type of conversation/discussion), details of the training programme (time frame of training programme, content, e.g. supervisory support), HCP outcome (assessment of communicative behaviours) and patient outcomes (anxiety, satisfaction with communication, quality of life). Two reviewers (R. U. and T. v. A.) independently assessed the methodological quality of the included studies using the criteria of the Cochrane EPOC Group (http://www.epoc.cochrane.org/). Disagreement among the reviewers was resolved by discussion. To ensure standardised scoring of study quality and data 
Uitterhoeve, R., Bensing, J., Grol, R., deMulder, P., Achterberg, T. van. The effect of communication skills 7 training on patient outcomes in cancer care: a systemtatic review of the literature. European Journal of:eanc Care: 2009

extraction, a pilot-tested predesigned table was used.

\section{Statistical analyses}

A meta-analysis was not feasible for the studies identified, because of heterogeneity of the content and design of the training programmes evaluated, as well as the outcome measures used. Furthermore, the presentation of outcomes made accurate extraction of raw data impossible, and the pooling of results was therefore neither possible nor appropriate. The characteristics of studies were tabulated and results qualitatively synthesised. Where studies reported adequate data, statistical analyses were performed using the random effects model. Results were expressed as relative risks (RRs) for dichotomous outcomes and standardised mean differences (SMD) for continuous outcomes with 95\% confidence intervals (CI), using the means and standard deviations of treatment and control groups in the formula of Cohen's $d=\left(\mathrm{M}_{1}-\mathrm{M}_{2}\right) / \sigma_{\text {pooled }}$, where $\sigma_{\text {pooled }}=\sqrt{ }\left[\left(\sigma_{1}{ }^{2}+\sigma_{2}{ }^{2}\right) / 2\right]$ (Hall \& Rosenthal 1995). For effect sizes, a score of 0 indicates no difference between intervention and control. For the RR, this is indicated by a score of 1 . To control for possible baseline differences between control and training group, we also calculated effect sizes between the groups at baseline.

To determine the clinical significance of effects that were expressed as RR, the number needed to treat (NNT) with 95\% CI was calculated. When expressed as SMD with 95\% CI, the point-, and intervalestimate was compared with the criterion that a difference of 0.5 or more is considered clinically relevant (Cohen 1988).

\section{RESULTS}

A total of seven studies were identified for inclusion in the review. The search of Medline, PsychInfo and Cinahl databases provided a total of 4010 citations. After adjusting for duplicates, 3952 were discarded because after reviewing the abstracts, it appeared that these papers did not meet the criteria. No additional studies were identified by checking references of located, relevant papers or searching for studies that cited the located, relevant papers. One unpublished study (Kruijver et al. 2001b) was obtained. The full text versions of the remaining 59 papers were examined in more detail. It appeared that 49 papers did not meet the inclusion criteria as described. Reasons for exclusion are summarised in Table 3. In the Method section of two papers (Heaven \& Maguire 1996; Fallowfield et al. 2002), it was reported that patient outcomes were measured; however, these outcomes were not presented or retrieved.

\section{[TABLE 3]}

Ten papers (Kruijver et al. 2001b; Jenkins \& Fallowfield 2002; Hulsman et al. 2002; Razavi et al. 2003; Shilling et al. 2003; Delvaux et al. 2004, 2005; Liénard et al. 2006; Brown et al. 2007; Lienard et al. 2008) were included in this review. The papers by Jenkins and Fallowfield (2002) and Shilling et al. (2003) reported on the same study; Shilling et al. reported the effect of a communication training programme on patient outcomes and Jenkins and Fallowfield reported the effect of the same training programme on the communicative behaviour of the HCP. The papers by Delvaux et al. (2005) and Lienard et al. (2008) also reported on the same study; Delvaux et al. reported the effect of a training programme on the communicative behaviour of the HCP in a three-person interview (HCP, patient and relative) and patient satisfaction, while Liénard et al. reported the effect of the same communication training programme on patient distress.

Another two papers (Razavi et al. 2003; Liénard et al. 2006) also reported outcomes regarding one study; Razavi et al. (2003) published HCP communicative behaviour and patient satisfaction outcomes, while Liénard et al. (2006) reported the outcomes on patient distress. The 10 included papers thus represented seven studies.

\section{Description of included studies}

Characteristics of the seven included studies are shown in Table 4. Five studies (Kruijver et al. 2001b; Jenkins \& Fallowfield 2002; Razavi et al. 2003; Shilling et al. 2003; Delvaux et al. 2004, 2005; Liénard et al. 2006; Lienard et al. 2008) used a randomisation procedure to allocate the training programme, one study (Brown et al. 2007) used a pre-test, post-test design and one study (Hulsman et al. 2002) used a repeated measurement design. 
Uitterhoeve, R., Bensing, J., Grol, R., deMulder, P., Achterberg, T. van. The effect of communication skills training on patient outcomes in cancer care: a systemtatic review of the literature. European Journal of Care: 2009

\section{[TABLE 4]}

\section{Methodological quality of the studies}

Concealment of allocation was found to be inadequate for two studies (Kruijver et al. 2001b; Delvaux et al. 2004) and unclear on the basis of the information provided for the other studies. The five randomised studies had similar groups at baseline for the key HCP performance and patient outcome measures. The dropout of HCP was considered acceptable, i.e. $20 \%$ or less or comparable between groups, in five studies (Kruijver et al. 2001b; Hulsman et al. 2002; Razavi et al. 2003; Delvaux et al. 2004, 2005; Liénard et al. 2006; Lienard et al. 2008) and unclear for one study (Jenkins \& Fallowfield 2002; Shilling et al. 2003). Protection against contamination between intervention and control group was considered inadequate for one study (Delvaux et al. 2004) and unclear for four studies (Kruijver et al. 2001b; Jenkins \& Fallowfield 2002; Razavi et al. 2003; Shilling et al. 2003; Delvaux et al. 2005; Liénard et al. 2006; Lienard et al. 2008). HCP performance outcomes were blindly assessed in six studies (Jenkins \& Fallowfield 2002; Hulsman et al. 2002; Razavi et al. 2003; Shilling et al. 2003; Delvaux et al. 2004, 2005; Liénard et al. 2006; Brown et al. 2007; Lienard et al. 2008). In the study of Kruijver et al. (2001b), HCP performance outcomes were not blindly assessed. Patient outcomes in the included studies were assessed by self-report questionnaires.

\section{Sample characteristics}

In five studies (Jenkins \& Fallowfield 2002; Hulsman et al. 2002; Razavi et al. 2003; Shilling et al. 2003; Delvaux et al. 2005; Liénard et al. 2006; Brown et al. 2007; Lienard et al. 2008), participants of the training programmes were oncologists and in two studies (Kruijver et al. 2001b; Delvaux et al. 2004) oncology nurses. In each study HCP participated on a voluntary basis. No studies with combined groups of nurses and oncologists were included. A total of $411 \mathrm{HCP}$ participated in the studies, with a mean of 59 HCP (range 10-115 HCP). The mean number of HCP allocated to the training groups was $37 \mathrm{HCP}$ (range 10-57 HCP). HCP communicative behaviour was assessed in a total of 1677 encounters with adult cancer patients. The patient outcome data were collected from a total of 3003 adult cancer patients ranging from 112 to 1816 patients.

\section{Setting}

Two studies (Kruijver et al. 2001b; Delvaux et al. 2004) were conducted in an inpatient setting. Two studies (Razavi et al. 2003; Delvaux et al. 2005; Liénard et al. 2006; Lienard et al. 2008) were conducted in a combination of in- and outpatient setting. Three studies (Hulsman et al. 2002; Jenkins \& Fallowfield 2002; Shilling et al. 2003; Brown et al. 2007) were conducted in an outpatient setting.

\section{Training programme}

Six training programmes (Kruijver et al. 2001b; Jenkins \& Fallowfield 2002; Razavi et al. 2003; Shilling et al. 2003; Delvaux et al. 2004, 2005; Liénard et al. 2006; Brown et al. 2007, Lienard et al. 2008 ) involved real-time training. The median duration of these programmes was $30.5 \mathrm{~h}$ (range $18-$ $105 \mathrm{~h}$ ). Role-playing exercises with regular feedback were part of these training programmes. The group size ranged from three to 15 participants, the latter being quite large. All but one study (Jenkins \& Fallowfield 2002; Shilling et al. 2003), explicitly mentioned theoretical education as a teaching strategy of the training. One training programme (Hulsman et al. 2002) involved computer-assisted instruction consisting of four modules; basic communication skills, breaking bad news, effectively providing information and how to deal with patient's emotions. Each module consisted of video examples of poor and adequate communication, with practice questions about the video and immediate feedback. Each module of this programme could be completed within an hour.

Three studies (Kruijver et al. 2001b; Razavi et al. 2003; Delvaux et al. 2005; Liénard et al. 2006; Lienard et al. 2008) targeted the transfer of learned communication skills to the daily workplace. In the study of Kruijver et al. (Kruijver et al. 2001b), one follow-up meeting was given 2 months after the training. Trainees were given the opportunity to exercise communication skills by role-play. In the remaining two studies (Razavi et al. 2003; Delvaux et al. 2005; Liénard et al. 2006; Lienard et al. 2008), 
Uitterhoeve, R., Bensing, J., Grol, R., deMulder, P., Achterberg, T. van. The effect of communication skills training on patient outcomes in cancer care: a systemtatic review of the literature. European Journal of:eanc Care: 2009

considerably more attention was paid to the transfer of acquired skills. Especially since these studies aimed to assess the efficacy of six 3-h consolidation workshops after a basic training programme. The consolidation workshops consisted of role-plays, with systematic feedback based on clinical problems brought up by the trainees, opportunities to evaluate difficulties of transferring acquired skills to the workplace and stimulating the use of those skills.

\section{Outcome measurement}

The communicative behaviour of HCP was measured in real patient encounters. The number of patient interviews each HCP conducted at each assessment point ranged from one interview (Razavi et al. 2003; Delvaux et al. 2004, 2005; Liénard et al. 2006; Lienard et al. 2008) to six interviews in the study of Kruijver et al. (2001b). Patient interviews were audio-, or video-recorded. Video-recordings were used in three studies (Kruijver et al. 2001b; Hulsman et al. 2002; Jenkins \& Fallowfield 2002; Shilling et al. 2003).

Five different observational instruments were used to code and analyse interactions between HCP and cancer patients, i.e. the Cancer Research Campaign Interview Rating Manual (CRCIRM) (Razavi et al. 2003; Caris-Verhallen et al. 2004; Delvaux et al. 2004, 2005; Liénard et al. 2006; Lienard et al. 2008), the Roter Interaction Analysis System (Kruijver et al. 2001b; Roter \& Larson 2002; Caris-Verhallen et al. 2004), the Medical Interaction Process System (MIPS) (Ford et al. 2000; Jenkins \& Fallowfield 2002; Shilling et al. 2003; Ford \& Hall 2004), the Communication Rating System (Hulsman et al. 2002) and a system to code oncologists communicative behaviours to gain informed consent for trial participation (Brown et al. 2004, 2007). The smallest number of categories of the described observational instruments that were used in the included studies was four in the study by Brown et al. (2007) and the Jenkins \& Shilling study (Jenkins \& Fallowfield 2002; Shilling et al. 2003). The latter, who selected four a priori behaviours of interest from the MIPS, namely appropriate responses to patient cues, psychosocial probing, empathic statements and use of open questions. Kruijver et al. (2001b) used the largest number, namely 37 behavioural outcome categories.

Regarding patient outcomes, patient satisfaction was used as an outcome measure in the seven included studies. Seven different patient satisfaction questionnaires were used, i.e. the Patient Satisfaction with the Interview Assessment Questionnaire (Delvaux et al. 2004), the Patients' Perception of the Interview Questionnaire (Razavi et al. 2003), the Patient Satisfaction with Communication Questionnaire (Jenkins \& Fallowfield 2002; Shilling et al. 2003), the Patient Satisfaction Questionnaire (PSQ) (Kruijver et al. 2001b), the Patient and Relative Perception of the Interview Questionnaire (Delvaux et al. 2005; Lienard et al. 2008), the PSQ (Brown et al. 2007) and the Medical Interview Satisfaction Scale (Hulsman et al. 2002). The number of items on the satisfaction questionnaires ranged from seven in the study of (Kruijver et al. (2001b) to 29 in the study of Hulsman et al. (2002). In the studies of Shilling et al. (2003), Hulsman et al. (2002) and Brown et al. (2007), an overall satisfaction score was used as the patient satisfaction outcome measure.

Three studies (Razavi et al. 2003; Delvaux et al. 2005; Liénard et al. 2006; Brown et al. 2007; Lienard et al. 2008) also used patient distress as an outcome which was measured with the State Trait Anxiety Inventory - State version (STAI-S). Kruijver et al. (2001b) used quality of life (QLQ-C30) as a patient outcome measure.

\section{Outcomes}

\section{HCP communicative behaviour}

Training effects on the behavioural outcomes were found in six of the seven included studies (Table 4). The study of Kruijver et al. (2001b) showed no training effects on any of the measured behavioural categories. In the study of Hulsman et al. (2002), several statistically significant effects were found on the quantitative and qualitative judgement ratings, but not on the frequencies of the behavioural categories. Hulsman et al. did not report the required data to facilitate the calculation of RR or SMD. Brown et al. (2007) reported a statistically significant increase in the use of behaviours from one of four categories, i.e. the shared decision-making category. This finding was reported as an SMD with $95 \% \mathrm{CI}$ (see Fig. 1), i.e. 0.48 (95\% CI: 0.04 to 0.92 ). Razavi et al. (2003) reported statistically significant improvement for four of 22 behavioural categories. Delvaux et al. in the 2004 study (Delvaux et al. 2004) reported a statistically significant improvement of one of 15 behavioural categories at the post- 
Uitterhoeve, R., Bensing, J., Grol, R., deMulder, P., Achterberg, T. van. The effect of communication skills training on patient outcomes in cancer care: a systemtatic review of the literature. European Journal of Care: 2009

training assessment, which remained significant at the 6-month follow-up assessment. The 2005 study of Delvaux et al. (2005) showed statistically significant improvement for 11 of 16 patient-directed behaviours. Although the three studies (Razavi et al. 2003; Delvaux et al. 2004, 2005) used the same measurement instrument, i.e. the CRCIRM, studies were not sufficiently similar to synthesise the outcomes quantitatively. Delvaux et al. (2004) examined the effect of communication training, while Razavi et al. (2003) examined the effect of communication training followed by consolidation workshops and Delvaux et al. (2005) examined effects on HCP communicative behaviour in a threeperson interview. Statistically significant results for the studies of Delvaux et al. (2004) and Razavi et al. (2003) were expressed as SMD, with 95\% CI (see Fig. 1). The SMD ranged from 0.18 (95\% CI: -0.34 to 0.69 ) for acknowledgement in the study of Razavi to 0.74 (95\% CI: 0.35 to 1.14 ) for educated guesses in the study of Delvaux. It is noticed that calculation of the SMD altered the significance of three outcomes that were reported as statistically significant in the original study of Razavi et al. (2003). Statistically significant results of the 2005 study of (Delvaux et al. (2005) were reported as RRs, with 95\% CI. RRs ranged from 1.21 (95\% CI: 1.03 to 1.42) for acknowledgement to 4.96 (95\% CI: 2.42 to 10.13) for eliciting and clarifying psychological information (see Fig. 2). It is noticed that these outcomes involve RR of a MANOVAgroup-by-time analysis. Delvaux et al. (2005) did not report the required data to facilitate the calculation of RR based on post-training comparison of HCP behaviour in the control versus training group.

\section{[FIGURE 1] AND [FIGURE 2]}

One study (Jenkins \& Fallowfield 2002) apriori selected a limited number of four binary behavioural outcomes. These outcomes were expressed as RRs, with 95\% CI (see Fig. 2). RRs ranged from 1.26 ( $95 \%$ CI: 1.09 to 1.46) for use of open questions to 1.74 (95\% CI: 0.97 to 3.12 ) for psychosocial probing. Here it is observed that the significance of one outcome, i.e. psychosocial probing, was altered by the calculation of the RR.

\section{Patient outcomes}

Training effects on patient satisfaction outcomes were found in three of seven included studies (Table 4). Four studies (Kruijver et al. 2001b; Hulsman et al. 2002; Shilling et al. 2003; Brown et al. 2007) showed no training effects on patient satisfaction. Both (Razavi et al. (2003) and Delvaux et al. (2005) reported statistically significant improvements on one of nine patient satisfaction dimensions. Delvaux et al. (2004) reported statistically significant improvement on two of five patient satisfaction dimensions both after training and at 6-month follow-up. These results were expressed as SMD, with $95 \%$ CI (see Fig. 3) and ranged from 0.07 (95\% CI: -0.30 to 0.44 ) for satisfaction with information and support to 0.70 (95\% CI: 0.16 to 1.24) for satisfaction with the assessment of concerns. Note that calculation of the SMD altered the significance of four outcomes that were reported as statistically significant in the original studies. Delvaux et al. (2005) also reported a statistically significant training effect on the overall patient satisfaction with the interview (one item), but did not provide the required data to facilitate the calculation of an SMD.

\section{[FIGURE 3]}

None of the four included studies that had patient distress or quality of life as an outcome measure reported significant training effects on any of these measures (see Table 4).

\section{Baseline analyses}

There were no baseline differences between training and intervention groups in HCP communicative behaviour ( $P$-values between 0.13 and 0.59 ). The only significant baseline differences were found among the patient satisfaction outcomes (Razavi et al. 2003; Delvaux et al. 2005). In the one study (Razavi et al. 2003), the satisfaction of patients with the physicians' perception of the patients' understanding of the disease at baseline was significantly higher in the control group than in the intervention group ( $d=-0.65,95 \% \mathrm{CI}-1.18$ to -0.13$)$. In the other study (Delvaux et al. 2005) overall patient satisfaction with the interview at baseline was significantly higher in the intervention group compared with the control group ( $\mathrm{d}=0.66,95 \%$ CI 0.12 to 1.20$)$. No other baseline differences in 
Uitterhoeve, R., Bensing, J., Grol, R., deMulder, P., Achterberg, T. van. The effect of communication skills training on patient outcomes in cancer care: a systemtatic review of the literature. European Journal of:eanc Care: 2009

patient satisfaction outcomes were found.

\section{Clinical significance}

The outcomes expressed as SMD with 95\% CI were compared with the criterion that a difference of 0.5 represents a clinically relevant difference. The $95 \%$ CI corresponds with a pessimistic to optimistic scenario regarding effect of training, while the actual point estimate involves the intermediate scenario. Regarding effects on HCP behaviour (Fig. 1), outcomes indicate that in an optimistic scenario all seven outcomes represent a clinically relevant difference. In a pessimistic scenario, none of the seven outcomes represent a clinically relevant difference, while in the intermediate scenario three of seven outcomes appeared clinically relevant. When effects were expressed as RR the NNT with $95 \%$ CI was calculated to give an indication on the clinical relevance (see Table 5). In an optimistic scenario, NNT ranged from three to four, indicating that three to four HCP need to be trained for one HCP to attain the skills involved, while in a pessimistic scenario for one HCP to attain these skills, 13 to an infinitely large number of HCP need to be trained. In the intermediate scenario, the NNT ranged from five HCP for appropriate responding cue responding to nine HCP for psychosocial probing. Delvaux et al. (2005) did not provide the required data to calculate the NNT.

\section{[TABLE 5]}

Regarding patient satisfaction outcomes (see Fig. 3), which were expressed as SMD, four of seven outcomes were clinically relevant in an optimistic scenario, none in the pessimistic scenario, while in the intermediate scenario only the effect on patient satisfaction with the assessment of concerns was clinically relevant.

\section{DISCUSSION}

The aim of this review was to clarify the effectiveness of communication training for oncology HCP to improve patient outcomes. A striking finding of our review is that despite extensive literature searching, only seven studies met the review's inclusion criteria, all of which were published since 2001. It would appear that the effect of communication skills training for HCP on patient outcomes has only recently become of interest to researchers. When interpreting the findings of this review, it should be taken into consideration that inclusion of studies was limited to studies that had patient outcomes as an endpoint. This means that no definite conclusions can be drawn about the effect of communication training programmes on HCP communication skills in real patient encounters. Moreover, it has been shown elsewhere that communication training is effective in establishing improvement in HCP communicative behaviour (Fellowes et al. 2004; Gysels et al. 2004). The current review yielded several statistically significant improvements on both patient satisfaction and HCP communicative behaviour. Yet, the extent to which these benefits are clinically significant remain inconclusive. No evidence could be found for an effect (either positive or negative) as a result of communication skills training on patient distress.

Several reasons may account for the somewhat disappointing results of this review. It appeared that most studies (Kruijver et al. 2001b; Razavi et al. 2003; Delvaux et al. 2004, 2005) used multiple behavioural outcome categories. It can be suggested that one weakness of these studies is that by performing multiple comparisons they risked concluding that communication training had an effect when no true effect exists. Because of the use of multiple behavioural outcome categories, the connection with patient outcomes has been obscured. It appears that the combination of training goals with content of the programme and patient outcome variables is scarcely based on available theory and knowledge. It is recommended that future trials determine a primary outcome, preferably reported as a single measure and based on available theory and knowledge. Moreover, it might be fruitful to develop and subsequently evaluate a training programme within the context of a theoretical framework, such as that by Feldman-Stewart et al. (Carlson et al. 2005; Feldman-Stewart et al. 2005). This framework proposes four key components around which HCP communication in cancer care can be investigated. These are the focus of the interaction, the patients and HCP themselves with their needs, skills, values, beliefs and emotions, the communication process and finally, the environment in which the communication occurs.

There is ample evidence that patients value patient-centred communication, i.e. that their (emotional) 
Uitterhoeve, R., Bensing, J., Grol, R., deMulder, P., Achterberg, T. van. The effect of communication skills training on patient outcomes in cancer care: a systemtatic review of the literature. European Journal of Care: 2009

needs are recognised and responded to appropriately (Suchman et al. 1997; Levinson et al. 2000; Lewin et al. 2001; Bub 2004; Beach et al. 2005; Hack et al. 2005). Perhaps this signifies an important tenet to incorporate in future communication training programmes; namely, that it is pivotal for patient-centred communication to recognise that patients provide cues to their feelings, fears and expectations and subsequently to respond appropriately. This may lead to further disclosure and improvement of satisfaction with communication. This should be reflected in the choice of behavioural outcome categories.

Another reason why communication training failed to elicit consistently significant changes on HCP communication behaviours and patient outcomes, concerns the absence of adequate transfer strategies in the training design. Transfer strategies are strategies that support the transfer of acquired skills from training to the workplace environment. To be effective, these strategies should be directed towards factors that affect the transfer process. Since in most cases, there is a range of facilitating and hindering factors, a combination of approaches seems to be the most effective way to establish transfer (Grol \& Grimshaw 2003; Wensing \& Grol 2005). Moreover, it seems crucial to pay attention to the contextual and organisational characteristics of the environment where the learned skills need to be applied, especially the provision of supervisory support seems pivotal (Baldwin \& Ford 1988; Booth et al. 1996; Kruijver et al. 2001b; van Weert et al. 2004). For instance, when nurses feel unsupported by management to use the newly acquired communication skills, it is highly unlikely that the new skills will be applied and probably the learned behaviours will be lost (McCabe 2004). Although three studies in the current review more or less targeted the transfer of acquired skills, none of the included studies incorporated strategies in the training design to enhance or strengthen the provision of supervisory support. To establish the transfer of acquired communicative skills, it is recommended that training programmes incorporate interventions to accomplish attitudinal change in ward culture and managerial emphasis, so that the contribution of patient-centred communication to quality care is better recognised. It is recommended that ward managers be given adequate training to provide supervisory support to their employees who attend a communication skills training programme. This may be a window towards improving the actual performance of acquired communicative skills and patient satisfaction with communication.

Yet, another reason for the lack of results in this review involves the measurement of the outcomes in the studies. In studies (Delvaux et al. 2004, 2005; Lienard et al. 2008; Razavi et al. 2003; Liénard et al. 2006) in which each HCP interviewed only one patient at each assessment point, patient factors have a greater influence on outcome categories than in studies in which each HCP interviewed several patients at each assessment point. In those studies, the variation in patient factors is better controlled for. In addition, concerning the measurement of patient satisfaction, different measurement instruments were used. Although these instruments were all directed towards satisfaction with communication, little was done in any of the included studies to prevent scoring at the ceiling of the patient satisfaction scales. This resulted in limited variation between the groups. This phenomenon is a well-known problem when measuring patient satisfaction. For further research, it is recommended to use patient satisfaction scales that can yield variation in item responses. For instance, by limiting the patients' frame of reference to satisfaction with HCP communicative behaviour at a specific point in time when responding to patientquestionnaire items (Hendriks et al. 2002, 2004). A fundamentally different and promising approach is proposed by Sixma et al. (1998), who developed a conceptual framework for measuring patient satisfaction. In this approach, patients attach importance and performance scores to different healthcare aspects. Performance relates to the actual patients' experience of the HCP behaviour or healthcare services. Importance refers to the fact that different patients value different aspects of HCP behaviour or health services. Instruments that are based on this framework, i.e. QUOTE-questionnaires, yield more variation in the patients' rating of the quality of care (Jacobi et al. 2004; Pieterse et al. 2005). Measuring cancer patients' satisfaction with the communication of HCP along the lines of this framework might therefore be more sensitive in measuring change.

A last consideration concerns the statistical analyses performed in this review. Our bivariate analyses of effect sizes reduced the number of statistically significant findings to four as compared with the 11 significant results of the multivariate analyses in the original studies of Delvaux et al. (2004) and Razavi et al. (2003). These multivariate analyses were conducted to correct for baseline differences. However, even though we found a trend towards baseline differences between training and control groups, these 
Uitterhoeve, R., Bensing, J., Grol, R., deMulder, P., Achterberg, T. van. The effect of communication skills training on patient outcomes in cancer care: a systemtatic review of the literature. European Journal of:eanc Care: 2009

differences were in fact not statistically significant. Therefore, it can be argued that our approach of calculating effects sizes with $95 \%$ CI reflects the more realistic chance of improving communicative behaviour and patient satisfaction.

In conclusion, there is little evidence that communication training programmes which aim at improving HCP communicative behaviour are uniformly effective in improving patient outcomes. There is a pressing need to ensure that communication training programmes are accompanied by good quality randomised evaluations in which:

- The goals and content of the training programme are conceptually linked to outcomes that are important to patients and $\mathrm{HCP}$.

- A primary outcome is chosen, preferably operationalised as a single measure.

- The training programme incorporates activities to promote the transfer of acquired skills into daily practice, preferably activities to strengthen the provision of supervisory support to participants of the programme.

\section{REFERENCES}

Abel J., Dennison S., Senior Smith G., Dolley T., Lovett J. \& Cassidy S. (2001) Breaking bad news development of a hospital-based training workshop. The Lancet Oncology 2, 380-384.

Alexander S.C., Keitz S., Sloane R. \& Tulsky J.A. (2006) A controlled trial of a short course to improve residents' communication with patients at the end of life. End of Life Care 81, 1008-1012.

Andersen C. \& Adamsen L. (2001) Continuous video recording: a new clinical research tool for studying the nursing care of cancer patients. Journal of Advanced Nursing 35, 257-267.

Argent J., Faulkner A., Jones A. \& O'Keeffe C. (1994) Communication skills in palliative care: development and modification of a rating scale. Medical Education 28, 559-565.

Back A.L., Arnold R.M., Baile W.F., Fryer-Edwards K.A., Alexander S.C., Barley G.E., Gooley T.A. \& Tulsky J.A. (2007) Efficacy of communication skills training for giving bad news and discussing transitions to palliative care. Archives of Internal Medicine 167, 453-460.

Baile W.F., Lenzi R., Kudelka A.P., Maguire P., Novack D., Goldstein M., Myers E.G. \& Bast R.C.J. (1997) Improving physician-patient communication in cancer care: outcome of a workshop for oncologists. Journal of Cancer Education 12, 166-173.

Baile W.F., Kudelka A.P., Beale E.A., Glober G.A., Myers E.G., Greisinger A.J., Bast R.-C.J., Goldstein M.G., Novack D. \& Lenzi R. (1999) Communication skills training in oncology. Description and preliminary outcomes of workshops on breaking bad news and managing patient reactions to illness. Cancer 86, 887-897.

Baldwin T.T. \& Ford J.K. (1988) Transfer of training: a review and directions for future research. Personnel-Psychology 41, 63-105.

Beach W.A., Easter D.W., Good J.S. \& Pigeron E. (2005) Disclosing and responding to cancer 'fears' during oncology interviews. Social Science and Medicine 60, 893-910.

Bensing J. (1991) Doctor-patient communication and the quality of care. Social Science and Medicine 32, 1301-1310.

Booth K., Maguire P.M., Butterworth T. \& Hillier V.F. (1996) Perceived professional support and the use of blocking behaviours by hospice nurses. Journal of Advanced Nursing 24, 522-527.

Brown R.F., Butow P.N., Henman M., Dunn S.M., Boyle F. \& Tattersall M.H. (2002) Responding to the active and passive patient: flexibility is the key. Health Expectations 5, 236-245.

Brown R.F., Butow P.N., Ellis P., Boyle F. \& Tattersall M.H. (2004) Seeking informed consent to cancer clinical trials: describing current practice. Social Science and Medicine 58, 2445-2457.

Brown R.F., Butow P.N., Boyle F. \& Tattersall M.H. (2007) Seeking informed consent to cancer clinical trials; evaluating the efficacy of doctor communication skills training. Psychosocial Oncology 16, 507516.

Bub B. (2004) The patient's lament: hidden key to effective communication: how to recognise and transform. Medical Humanities 30, 63-69

Butow P.N., Brown R.F., Cogar S., Tattersall M.H.N. \& Dunn S.M. (2002a) Oncologists' reactions to cancer patients' verbal cues. Psychosocial Oncology 11, 47-58.

Butow P.N., Dowsett S., Hagerty R. \& Tattersall M.H. (2002b) Communicating prognosis to patients with metastatic disease: what do they really want to know? Supportive Care in Cancer 10, 161-168.

Caris-Verhallen W., Timmermans L. \& van Dulmen S. (2004) Observation of nurse-patient interaction in oncology: review of assessment instruments. Patient Education and Counseling 54, 307-320.

Carlson L.E., Feldman-Stewart D., Tishelman C. \& Brundage M.D. (2005) Patient-professional 
Uitterhoeve, R., Bensing, J., Grol, R., deMulder, P., Achterberg, T. van. The effect of communication skills 7 training on patient outcomes in cancer care: a systemtatic review of the literature. European Journal of:eanc Care: 2009

communication research in cancer: an integrative review of research methods in the context of a conceptual framework. Psychosocial Oncology 14, 812-828.

Coffman S.L. \& Coffman V.T. (1993) Communication training for hospice volunteers. Omega: Journal of Death and Dying 27, 155-163.

Cohen J. (1988) Statistical Power Analysis for the Behavioral Sciences, 2nd edn Lawrence Erlbaum, Lawrence Erlbaum Associates Inc., Hillsdale, NJ, USA.

Cowan D.H. \& Laidlaw J.C. (1993) A strategy to improve communication between health care professionals and people living with cancer. I. Improvement of teaching and assessment of doctorpatient communication in Canadian medical schools. Journal of Cancer Education 8, 109-117.

Cowan D.H., Laidlaw J.C. \& Russell M.L. (1997) A strategy to improve communication between health care professionals and people living with cancer: II. Follow-up of a workshop on the teaching and assessment of communication skills in Canadian Medical Schools. Journal of Cancer Education 12, 161-165.

Delvaux N. \& Razavi D. (1997) Psychological training for health-care professionals in oncology. A way to improve communication skills. Annals of the New York Academy of Sciences 809, 336-349.

Delvaux N., Razavi D., Marchal S., Bredart A., Farvacques C. \& Slachmuylder J.L. (2004) Effects of a $105 \mathrm{~h}$ psychological training program on attitudes, communication skills and occupational stress in oncology: a randomised study. British Journal of Cancer 90, 106-114.

Delvaux N., Merckaert I., Marchal S., Libert Y., Conradt S., Boniver J., Etienne A.M., Fontaine O., Janne P., Klastersky J., Melot C., Reynaert C., Scalliet P., Slachmuylder J.L. \& Razavi D. (2005) Physicians' communication with a cancer patient and a relative: a randomized study assessing the efficacy of consolidation workshops. Cancer 103, 2397-2411.

Dennison S. (1995) An exploration of the communication that takes place between nurses and patients whilst cancer chemotherapy is administered. Journal of Clinical Nursing 4, 227-233.

Fallowfield L., Lipkin M. \& Hall A. (1998) Teaching senior oncologists communication skills: results from phase I of a comprehensive longitudinal program in the United Kingdom. Journal of Clinical Oncology 16, 1961-1968.

Fallowfield L., Saul J. \& Gilligan B. (2001) Teaching senior nurses how to teach communication skills in oncology. Cancer Nursing 24, 185-191.

Fallowfield L., Jenkins V., Farewell V., Saul J., Duffy A. \& Eves R. (2002) Efficacy of a Cancer Research UK communication skills training model for oncologists: a randomised controlled trial. The Lancet 359 , 650-656.

Fallowfield L., Jenkins V., Farewell V. \& Solis Trapala I. (2003) Enduring impact of communication skills training: results of a 12-month follow-up. British Journal of Cancer 89, 1445-1449.

Farrell C., Heaven C., Beaver K. \& Maguire P. (2005) Identifying the concerns of women undergoing chemotherapy. Patient Education and Counseling 56, 72-77.

Faulkner A., Argent F., Jones A. \& O'Keeffe C. (1995) Improving the skills of doctors in giving distressing information. Medical Education 29, 303-307.

Favre N., Despland J.N., de Roten, Y., Drapeau M., Bernard, M. \& Stiefel F. (2007) Psychodynamic aspects of communication skills training: a pilot study. Supportive Care in Cancer 15, 333-337.

Feldman-Stewart D., Brundage M.D. \& Tishelman C. (2005) A conceptual framework for patientprofessional communication: an application to the cancer context. Psychosocial Oncology 14, 801809.

Fellowes D., Wilkinson S. \& Moore P. (2004) Communication skills training for health care professionals working with cancer patients, their families and/or carers. Cochrane Database of Systematic Reviews (Online) Issue 2, CD003751.

Finset A., Ekeberg O., Eide H. \& Aspegren K. (2003) Long term benefits of communication skills training for cancer doctors. Psychosocial Oncology 12, 686-693.

Ford S. \& Hall A. (2004) Communication behaviours of skilled and less skilled oncologists: a validation study of the Medical Interaction Process System (MIPS). Patient Education and Counseling 54, 275282.

Ford S., Fallowfield L. \& Lewis S. (1996) Doctor-patient interactions in oncology. Social Science and Medicine 42, 1511-1519.

Ford S., Hall A., Ratcliffe D. \& Fallowfield L. (2000) The Medical Interaction Process System (MIPS): an instrument for analysing interviews of oncologists and patients with cancer. Social Science and Medicine 50, 553-566.

Fujimori M., Oba A., Koike M., Okamura M., Akizuki N., Kamiya M., Akechi T., Sakano Y. \& Uchitomi Y. (2003) Communication skills training for Japanese oncologists on how to break bad news. Journal of Cancer Education 18, 194-201.

Grol R. \& Grimshaw J. (2003) From best evidence to best practice: effective implementation of change in 
Uitterhoeve, R., Bensing, J., Grol, R., deMulder, P., Achterberg, T. van. The effect of communication skills training on patient outcomes in cancer care: a systemtatic review of the literature. European Journal of.eanc Care: 2009

patients' care. The Lancet 362, 1225-1230.

Gysels M., Richardson A. \& Higginson I.J. (2004) Communication training for health professionals who care for patients with cancer: a systematic review of effectiveness. Supportive Care in Cancer 12, 692700.

Hack T.F., Degner L.F. \& Parker P.A. (2005) The communication goals and needs of cancer patients: a review. Psychosocial Oncology 14, 831-845.

Hall J.A. \& Rosenthal R. (1995) Interpreting and evaluating meta-analysis. Evaluation and the Health Professions 18, 393-407.

Heaven C. (2001) The Role of Clinical Supervision in Communication Skills Training. Stanley House, Christie Hospital, Manchester: Psychological Medicine Group.

Heaven C., Clegg J. \& Maguire P. (2006) Transfer of communication skills training from workshop to workplace: the impact of clinical supervision. Patient Education and Counseling 60, 313-325.

Heaven C.M. \& Maguire P. (1996) Training hospice nurses to elicit patient concerns. Journal of Advanced Nursing 23, 280-286.

Heaven C.M. \& Maguire P. (1997) Disclosure of concerns by hospice patients and their identification by nurses. Palliative Medicine 11, 283-290.

Hellbom M., Brandberg Y., Kurland J., Arving C., Thalen Lindstrom A., Glimelius B. \& Sjoden P.O. (2001) Assessment and treatment of psychosocial problems in cancer patients: an exploratory study of a course for nurses. Patient Education and Counseling 45, 101-106.

Hendriks A.A.J., Oort F., Vrielink M. \& Smets E. (2002) Reliability and validity of the Satisfaction with Hospital Care Questionnaire. International Journal for Quality in Health Care 14, 471-482.

Hendriks A.A.J., Vrielink M.R., van Es S.Q., De Haes H.J.C.J. \& Smets E.M.A. (2004) Assessing inpatients' satisfaction with hospital care: should we prefer evaluation or satisfaction ratings? Patient Education and Counseling 55, 142-146.

Hietanen P.S., Aro A.R., Holli K.A., Schreck M., Peura A. \& Joensuu H.T. (2007) A short communication course for physicians improves the quality of patient information in a clinical trial. Acta Oncologica 46, $42-48$.

Hill K.M., Amir Z., Muers M.F., Connolly C.K. \& Round C.E. (2003) Do newly diagnosed lung cancer patients feel their concerns are being met? European Journal of Cancer Care 12, 35-45.

Hulsman R.L., Ros W.J., Janssen M. \& Winnubst J.A. (1997) INTERACT-CANCER. The development and evaluation of a computer-assisted course on communication skills for medical specialists in oncology. Patient Education and Counseling 30, 129-141.

Hulsman R.L., Ros W.J., Winnubst J.A. \& Bensing J.M. (2002) The effectiveness of a computer-assisted instruction programme on communication skills of medical specialists in oncology. Medical Education $36,125-134$.

Jacobi C.E., Boshuizen H.C., Rupp I., Dinant H.J., \& van den Bos G.A. (2004) Quality of rheumatoid arthritis care: the patient's perspective. International Journal for Quality in Health Care 16, 73-81.

Jarrett N.J. \& Payne S.A. (2000) Creating and maintaining 'optimism' in cancer care communication. International Journal of Nursing Studies 37, 81-90.

Jenkins V. \& Fallowfield L. (2002) Can communication skills training alter physicians' beliefs and behavior in clinics? Journal of Clinical Oncology 20, 765-769.

Kerr J., Engel J., Schlesinger Raab A., Sauer H. \& Holzel D. (2003) Doctor-patient communication: results of a four-year prospective study in rectal cancer patients. Diseases of the Colon and Rectum 46, 1038-1046.

Klein S., Tracy D., Kitchener H.C. \& Walker L.G. (2000) The effects of the participation of patients with cancer in teaching communication skills to medical undergraduates: a randomised study with follow-up after 2 years. European Journal of Cancer 36, 273-281.

Kruijver I.P.M., Kerkstra A., Francke A.L., Bensing J.M. \& van de Wiel H.B.M. (2000) Evaluation of communication training programs in nursing care: a review of the literature. Patient Education and Counseling 39, 129-145.

Kruijver I.P.M., Kerkstra A., Kerssens J.J., Holtkamp C.C.M., Bensing J.M. \& van de Wiel H.B.M. (2001a) Communication between nurses and simulated patients with cancer: evaluation of a communication training programme. European Journal of Oncology Nursing 5, 140-153.

Kruijver I.P.M., Kerssens J.J., Bensing J.M., van de Wiel H.B., Wind R.M., de Kruijf J.C.M. \& Marres H.A.M. (2001b) Communication Between Nurses and Admitted Cancer Patients: The Impact of a Communication Training Program on Nurse and Patient Outcomes. National Institute for Health Services Research, Utrecht, The Netherlands.

Kruse J., Schmitz N., Woller W., Clar B., Meyer E., Grinschgl A. \& Tress W. (2003) Effekte eines psychosozialen Fortbildungsprogramms zur Verbesserung der Arzt-Patient-Interaktion mit Krebspatienten. [Effects of a psychosocial education programme to improve doctor-patient interaction 
Uitterhoeve, R., Bensing, J., Grol, R., deMulder, P., Achterberg, T. van. The effect of communication skills 7 training on patient outcomes in cancer care: a systemtatic review of the literature. European Journal of.eanc Care: 2009

with cancer patients]. Zeitschrift für Psychosomatische Medizin und Psychotherapie 49, 232-245.

Ladouceur R., Goulet F., Gagnon R., Boule R., Girard G., Jacques A., Frenette J., Carrier R., Lalonde V. \& Belisle C. (2003) Breaking bad news: impact of a continuing medical education workshop. Journal of Palliative Care 19, 238-245.

Levinson W., Gorawara-Bhat R. \& Lamb J. (2000) A Study of Patient Clues and Physician Responses in Primary Care and Surgical Settings. Journal of the American Medical Association 284, 1021-1027. Lewin S., Skea Z., Entwistle V., Zwarenstein M. \& Dick J. (2001) Interventions for providers to promote a patient-centred approach in clinical consultations. The Cochrane Database of Systematic Reviews Issue 4, CD003267.

Lienard A., Merckaert I., Libert Y., Delvaux N., Marchal S., Boniver J., Etienne A.M., Klastersky J., Reynaert C., Scalliet P., Slachmuylder J.L. \& Razavi D. (2008) Factors that influence cancer patients' and relatives' anxiety following a three-person medical consultation: impact of a communication skills training program for physicians. Psychosocial Oncology 17, 488-496.

Liu J.E., Mok E., Wong T., Xue L. \& Xu B. (2007) Evaluation of an integrated communication skills training program for nurses in cancer care in Beijing, China. Nursing Research 56, 202-209.

Liénard A., Merckaert I., Libert Y., Delvaux N., Marchal S., Boniver J., Etienne A.M., Klastersky J., Reynaert C., Scalliet P., Slachmuylder J.L. \& Razavi D. (2006) Factors that influence cancer patients' anxiety following a medical consultation: impact of a communication skills training programme for physicians. Annals of Oncology 17, 1450-1458.

McCabe C. (2004) Nurse-patient communication: an exploration of patients' experiences. Journal of Clinical Nursing 13, 41-49.

Maguire P., Booth K., Elliott C. \& Jones B. (1996a) Helping health professionals involved in cancer care acquire key interviewing skills - the impact of workshops. European Journal of Cancer 32A, 14861489.

Maguire P., Faulkner A., Booth K., Elliott C. \& Hillier V. (1996b) Helping cancer patients disclose their concerns. European Journal of Cancer 32A, 78-81.

Ong M.L., Visser R.M., Lammes F.B. \& de Haes C.J.M. (2000) Doctor-patient communication and cancer patients' quality of life and satisfaction. Patient Education and Counseling 41, 145-156.

Parle M., Maguire P. \& Heaven C. (1997) The development of a training model to improve health professionals' skills, self-efficacy and outcome expectancies when communicating with cancer patients. Social Science and Medicine 44, 231-240.

Pieterse A., van Dulmen S., Ausems M., Schoemaker A., Beemer F. \& Bensing J. (2005) QUOTEgene(ca): development of a counselee-centered instrument to measure needs and preferences in genetic counseling for hereditary cancer. Psychosocial Oncology 14, 361-375.

Razavi D., Delvaux N., Marchal S., Bredart A., Farvacques C. \& Paesmans M. (1993) The effects of a 24-h psychological training program on attitudes, communication skills and occupational stress in oncology: a randomised study. European Journal of Cancer 29A, 1858-1863.

Razavi D., Delvaux N., Marchal S., De Cock M., Farvacques C. \& Slachmuylder J.L. (2000) Testing health care professionals' communication skills: the usefulness of highly emotional standardized roleplaying sessions with simulators. Psychosocial Oncology 9, 293-302.

Razavi D., Delvaux N., Marchal S., Durieux J.F., Farvacques C., Dubus L. \& Hogenraad R. (2002) Does training increase the use of more emotionally laden words by nurses when talking with cancer patients? A randomised study. British Journal of Cancer 87, 1-7.

Razavi D., Merckaert I., Marchal S., Libert Y., Conradt S., Boniver J., Etienne A.M., Fontaine O., Janne P., Klastersky J., Reynaert C., Scalliet P., Slachmuylder J.L. \& Delvaux N. (2003) How to optimize physicians' communication skills in cancer care: results of a randomized study assessing the usefulness of posttraining consolidation workshops. Journal of Clinical Oncology 21, 3141-3149.

Roter D. \& Larson S. (2002) The Roter interaction analysis system (RIAS): utility and flexibility for analysis of medical interactions. Patient Education and Counseling 46, 243-251.

Shilling V., Jenkins V. \& Fallowfield L. (2003) Factors affecting patient and clinician satisfaction with the clinical consultation: can communication skills training for clinicians improve satisfaction? Psychosocial Oncology 12, 599-611.

Sixma H.J., Kerssens J.J., Campen C.V. \& Peters L. (1998) Quality of care from the patients' perspective: from theoretical concept to a new measuring instrument. Health Expectations 1, 82-95.

St Claire L. (2000) Measuring communication skills of medical students to patients with cancer. British Journal of Medical Psychology 73, 99-116.

Stewart M., Brown J.B., Hammerton J., Donner A., Gavin A., Holliday R.L., Whelan T., Leslie K., Cohen I., Weston W. \& Freeman T. (2007) Improving communication between doctors and breast cancer patients. Annals of Family Medicine 5, 387-394.

Suchman A.L., Markakis K., Beckman H.B. \& Frankel R. (1997) A model of empathic communication in 
Uitterhoeve, R., Bensing, J., Grol, R., deMulder, P., Achterberg, T. van. The effect of communication skills training on patient outcomes in cancer care: a systemtatic review of the literature. European Journal of ean

Care: 2009

the medical interview. The Journal of the American Medical Association 277, 678-682.

Timmermans L.M., van der Maazen R.W., van Spaendonck K.P., Leer J.W. \& Kraaimaat F.W. (2006) Enhancing patient participation by training radiation oncologists. Patient Education and Counseling 63 , 55-63.

Uitterhoeve R., Duijnhouwer E., Ambaum B. \& Van Achterberg T. (2003) Turning toward the psychosocial domain of oncology nursing: a main problem analysis in the Netherlands. Cancer Nursing 26, 18-27.

van Weert J.C.M., Kerkstra A., van Dulmen A.M., Bensing J.M., Peter J.G. \& Ribbe M.W.M. (2004) The implementation of snoezelen in psychogeriatric care: an evaluation through the eyes of caregivers. International Journal of Nursing Studies 41, 397-409.

Wensing M. \& Grol R. (2005) 'Multifaceted interventions,' In: Improving Patient Care (eds Grol R., Wensing M. \& Eccles M.), pp. 197-206. Elsevier, Oxford, UK.

White M.K. \& Malik T. (1999) Teaching clinician-patient communication in the treatment of breast diseases. Journal of Women's Health 8, 39-44.

Wilkinson S. (1991) Factors which influence how nurses communicate with cancer patients. Journal of Advanced Nursing 16, 677-688.

Wilkinson S., Roberts A. \& Aldridge J. (1998) Nurse-patient communication in palliative care: an evaluation of a communication skills programme. Palliative Medicine 12, 13-22.

Wilkinson S., Bailey K., Aldridge J. \& Roberts A. (1999) A longitudinal evaluation of a communication skills programme. Palliative Medicine 13, 341-348.

Wilkinson S.M., Gambles M. \& Roberts A. (2002) The essence of cancer care: the impact of training on nurses' ability to communicate effectively. Journal of Advanced Nursing 40, 731-738.

Wilkinson S.M., Leliopoulou C., Gambles M. \& Roberts A. (2003) Can intensive three-day programmes improve nurses' communication skills in cancer care? Psychosocial Oncology 12, 747-759. 


\section{Medline}

[('Disclosure- '/all SUBHEADINGS in MIME,MIME) or 'Nonverbal-Communication- ' /all SUBHEADINGS in MIME,MJME) or ('Negotiating-'/all SUBHEADINGS in MIME,MJME) or ('Communication-Barriers'/WITHOUT SUBHEADINGS in MIME,MIME) or ('Verbal-Behavior-' all SUBHEADINGS in MIME,MIME) or

(communication- in MIME, MIME) or (explode

Professional-Patient-Relations'/all SUBHEADINGS in

MIME,MJME) or (interacti ${ }^{\star}$ in ab) or (cue ${ }^{*}$ in ab) or

(respondi ${ }^{*}$ in ab) or (communicat ${ }^{*}$ in ab)] and [(explode Education-Continuing'/all SUBHEADINGS in MIME,MJME) or (explode 'program-evaluation'/all subheadings in MIME, MJME) or (explode 'Teaching-'/ all SUBHEADINGS in MIME,MIME) or (train * in ab) or $\left(\right.$ program $^{*}$ in $\left.a b\right)$ or (teach ${ }^{*}$ in $\left.a b\right)$ or (educat ${ }^{*}$ in $\left.a b\right)$

['Medical-Oncology'/all SUBHEADINGS in MIME,MJME) or ('Oncology-Service-Hospital'/all SUBHEADINGS in MIME,MIME) or

'Cancer-Care-Facilities'/all SUBHEADINGS in MIME,MJME) or (explode 'Oncologic-Nursing'/all SUBHEADINGS in MIME,MIME) or (explode Neoplasms-'/all SUBHEADINGS in MIME,MIME) or (cancer* in ab) or (tumor ${ }^{\star}$ in ab) or (tumour ${ }^{*}$ in ab) or or (oncolog* in ab) or (palliati* in ab) or hospice* in abll

and

[(Randomised controlled trial in pt) or (controlled clinical trial in pt) or (randomised controlled trials i MIME,MJME) or (random allocation in MIME,MJME) or double-blind method in MIME,MIME) or (single-blind method in MIME,MIME) or (Clinical-Trial in pt) or clinical trials in MIMEMIME) or ("clinical trial') or

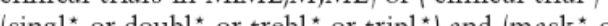
blind $\left.{ }^{*}\right)$ or ('latin square') or (placebos in MIME,MJME) or placebo* or random * or (research design in MIME,MJME) or (comparative study in MIME,MJME) o (evaluation studies in MIME,MIME) or

(follow-up-studies in MIME,MJME) or (prospective studies in MIME,MIME) or (cross-over-studies in

MIME,MIME) or control ${ }^{*}$ or prospective ${ }^{\star}$ or volunteer * or before ${ }^{\star}$ or after or longitudinal or pretest ${ }^{\star}$ or post ${ }^{\star}$ or evaluat* ${ }^{*}$ not [(animal in MIME,MIME) not (human in MIME,MJME)] not [(review in pt) or (meta-analysis in pt|l

Hits 2774
Cinahl

[(explode 'Teaching-'/all TOPICAL SUBHEADINGS/al] AGE SUBHEADINGS in DE) or (explode 'Program-Evaluation'/all TOPICAL SUBHEADINGS/all AGE SUBHEADINGS in DE) or (explode 'Education-'/al TOPICAL SUBHEADINGS/all AGE SUBHEADINGS in DE) or (train* in ti, ab) or (program * in ti, ab) or (teach * in $t i, a b)$ or (educat ${ }^{*}$ in $\left.\left.t i, a b\right)\right]$ and [( (explode

'Communication-'/all TOPICAL SUBHEADINGS/all AGE SUBHEADINGS in DE) or (explode

'Communication-Skills-Training'/all TOPICAL SUBHEADINGS/all AGE SUBHEADINGS in DE) or (interact ${ }^{\star}$ in ti, ab) or (communicat ${ }^{*}$ in ti, ab) or (cue * in ti, ab) or $\left(\right.$ respond $^{*}$ in ti, ab)] or (explode 'Professional-Patient-Relations'/all TOPICAL SUBHEADINGS/all AGE SUBHEADINGS in DE)] and

(explode 'Oncologic-Care'/all TOPICAL

SUBHEADINGS/all AGE SUBHEADINGS in DE) or (explode 'Neoplasms-'/all TOPICAL SUBHEADINGS/all AGE SUBHEADINGS in DE) or (explode 'Cancer-Patients'/all TOPICAL SUBHEADINGS/all AGE SUBHEADINGS in DE) or (explode 'Oncologic-Nursing'/all TOPICAL SUBHEADINGS/all AGE SUBHEADINCS in DE) or (cancer* in ti, ab) or

(tumor ${ }^{*}$ in $\mathrm{ti}, \mathrm{ab}$ ) or $\left(\right.$ tumour $^{*}$ in $\left.\mathrm{ti}, \mathrm{ab}\right)$ or $\left(\right.$ malign $^{*}$ in ab) or $\left(\right.$ oncolog $^{\star}$ in ti, ab) or (palliat ${ }^{\star}$ in ti, ab) or (hospice* in ti, ab) and

(explode 'Experimental-Studies'/all TOPICAL

SUBHEADINGS/all AGE SUBHEADINGS in DE) or [(single ${ }^{\star}$ or doubl ${ }^{\star}$ or treble ${ }^{\star}$ or tripl $\left.{ }^{*}\right)$ and $\left(\right.$ mask $^{*}$ or blind ${ }^{*}$ ] or (explode 'Quasi-Experimental-Studies- '/all TOPICAL SUBHEADINGS/all AGE SUBHEADINGS in DE) or (explode 'Prospective-Studies'/all TOPICAL SUBHEADINGS/all AGE SUBHEADINGS in DE) or (explode 'Crossover-Design'/all TOPICAL

SUBHEADINGS/all AGE SUBHEADINGS in DE) o (explode 'Repeated-Measures'/all TOPICAL

SUBHEADINGS/all AGE SUBHEADINGS in DE) or [(control ${ }^{\star}$ or prospective ${ }^{\star}$ or volunteer ${ }^{\star}$ or before ${ }^{\star}$ or longitudinal or pretest ${ }^{\star}$ ) in ti, ab
PsycInfo

[(explode 'On-the-Job-Training' in MJ,MN) or (explode 'Social-Skills-Training' in MJ,MN) or (explode 'Teaching-' in MJ,MN) or (explode

Communication-Skills-Training' in MJ,MN) or (explode 'Program-Evaluation' in MJ,MN) or (explode

Educational-Programs' in MI,MN) or (explode

'Educational-Program-Evaluation' in MI,MN) or (train " in ab) or (program * in ab) or (teach* in ab) or (educat ${ }^{*}$ in ab)

[(explode 'Neoplasms-' in MJ,MN) or (cancer* in ab) or (tumor ${ }^{\star}$ in $\mathrm{ab}$ ) or (tumour in ab) or (malign ${ }^{\star}$ in $\mathrm{ab}$ ) or (oncolog* in ab) or palliat* ${ }^{\star}$ or hospice* or (explode

'Palliative-Care' in MJ,MN)] and [(explode

'Verbal-Communication' in MJ,MN) or (explode

'Communication-Skills' in MJ,MN) or (explode

'Communication-' in $\mathrm{MJ}, \mathrm{MN}$ ) or (explode

'Interpersonal-Communication' in MJ,MN) or

(communicat ${ }^{*}$ in ab) or (interact ${ }^{*}$ in $\mathrm{ab}$ ) or (cue ${ }^{*}$ in $\mathrm{ab}$ or (respondi* in ab)]

(explode 'Experimental-Design' in MJ,MN) or (explode 'Treatment-Outcomes' in MJ,MN) or (explode

'Treatment-Effectiveness-Evaluation' in MI,MN) or

(explode 'Longitudinal-Studies' in MJ,MN) or (explode

'Placebo-' in MI,MN) or (control in ab) or (prospect ${ }^{\star}$ in

ab) or (volunteer ${ }^{\star}$ in ab) or (compar ${ }^{\star}$ in ab) or (random in ab) or (latin square in ab) or (placebo in ab) or

$\left(\right.$ longitud $\left.{ }^{\star}\right)$ or $\left(\right.$ pretest $\left.^{\star}\right)$ or (clinical trial) or [(FC:PPSYI $=$ CLINICAL-TRIAL) or (FC:PSYI =

DOUBLE-BLIND-DESIGN) or (FC:PSYI =

EMPIRICAL-STUDY) or (FC:PSYI =

EXPERIMENTAL-REPLICATION) or (FC:PSYI =

FOLLOWUP-STUDY) or (FC:PSYI =

LITERATURE-REVIEW) or (FC:PSYI =

LONGITUDINAL-STUDY) or (FC:PSYI =

META-ANALYSIS) or (FC:PSYI =

PROGRAM-EVALUATION) or (FC:PSYI =

PROSPECTIVE-STUDY) or (FC:PSYI $=$

SINGLE-BLIND-DESIGN) or (FC:PSYI =

TREATMENT-OUTCOMES|

Hits 345 
Uitterhoeve, R., Bensing, J., Grol, R., deMulder, P., Achterberg, T. van. The effect of communication skills training on patient outcomes in cancer care: a systemtatic review of the literature. European Journal of.eanc Care: 2009

Table 2. Inclusion and exclusion criteria

Inclusion criteria

- Population of HCP receiving communication training should consist of either nurses or doctors in oncology care.

- Studies should evaluate a communication skills training programme.

- The design of the studies evaluating communication training effectiveness should either have a controlled or a single group pretest-posttest study design.

- Presented outcomes should concern both $\mathrm{HCP}^{\prime}$ communicative behaviour in real patient encounters and patient outcomes.

Exclusion criteria

- Studies concerning training programmes not aiming at improving communicative behaviour of HCP, e.g. attitudes or knowledge.

HCP, healthcare professional.

Table 3. Excluded papers

Reasons for exclusion Studies

No controlled or single group 12 papers: Coffman \& Coffman 1993; Cowan \& Laidlaw 1993; Argent et al. 1994; Cowan et al. 1997; pretest-posttest study design Delvaux \& Razavi 1997; Heaven \& Maguire 1997; Jarrett \& Payne 2000; St Claire 2000; Brown et al. 2002; Butow et al. 2002a,b; Kerr et al. 2003

No HCP behaviours in real 2 papers: Hietanen et al. 2007; Stewart et al. 2007

patient encounters

No patient outcomes reported 35 papers: Razavi et al. 1993, 2000, 2002; Faulkner et al. 1995; Booth et al. 1996; Heaven \& Maguire 1996; Maguire et al. 1996a,b; Baile et al. 1997; Hulsman et al. 1997; Parle et al. 1997; Wilkinson et al. 1998, 1999, 2002, 2003; Baile et al. 1999; Fallowfield et al. 1998; White \& Malik 1999; Klein et al. 2000; Abel et al. 2001; Fallowfield et al. 2001; Hellbom et al. 2001; Kruijver et al. 2001a; Fallowfield et al. 2002; Fallowfield et al. 2003; Finset et al. 2003; Fujimori et al. 2003; Kruse et al. 2003;

Ladouceur et al. 2003; Alexander et al. 2006; Heaven et al. 2006; Timmermans et al. 2006; Back et al. 2007; Favre et al. 2007; Liu et al. 2007

HCP, healthcare professional. 
Table 4. Included studies

\begin{tabular}{|c|c|c|c|c|c|c|c|}
\hline Study feature & Brown et al, 2007 & Delvaux et al. 2004 & $\begin{array}{l}\text { Delvaux et al. } 2005 \text { \& } \\
\text { Lienard et al. } 2008\end{array}$ & Hulsman et al. 2002 & Kruijver et al. 2001b & $\begin{array}{l}\text { Razavi et al. } 2003 \text { \& } \\
\text { Liénard et al. } 2006\end{array}$ & $\begin{array}{l}\text { Jenkins \& Fallowfield } \\
2002 \text { \& Shilling et al. } \\
2003\end{array}$ \\
\hline Design & SGPP & RCT & RCT & $\begin{array}{l}\text { Repeated measurement } \\
\text { design }\end{array}$ & RCT & RCT & RCT \\
\hline$n$ (patients) & 90 & 335 & 56 & 385 & 265 & 118 & 372 \\
\hline Subject group & Adult cancer patients & Adult cancer patients & $\begin{array}{l}\text { Adult cancer patients } \\
\text { and relative }\end{array}$ & Adult cancer patients & Adult cancer patients. & Adult cancer patients & Adult cancer patients \\
\hline Age of subjects (SD) & $55(-)$ & $>18$ years old & $\begin{array}{l}\text { patients } 61.1(-)_{j} \\
\text { relatives } 58.3(-)\end{array}$ & $45.4(7.7)$ & $55.9(-)$ & $>18$ years old & $75 \%>44$ years \\
\hline$n(\mathrm{HCP})$ & $\begin{array}{l}10 \text { (oncologists)- } \\
\text { voluntary }\end{array}$ & 115 (nurses)-voluntary & $\begin{array}{l}62 \text { (specialist } \\
\text { physicians)-voluntary }\end{array}$ & $\begin{array}{l}21 \text { (physicians)- } \\
\text { voluntary }\end{array}$ & 51 (nurses)-voluntary & $\begin{array}{l}59 \text { (physicians)- } \\
\text { voluntary }\end{array}$ & $\begin{array}{l}93 \text { (oncologists)- } \\
\text { voluntary }\end{array}$ \\
\hline Setting & $\begin{array}{l}\text { Outpatient - informed } \\
\text { consent consultation }\end{array}$ & Inpatient & $\begin{array}{l}\text { In/outpatient (breaking } \\
\text { bad, neutral or good } \\
\text { news) }\end{array}$ & Outpatient & $\begin{array}{l}\text { Inpatient - admission } \\
\text { interview }\end{array}$ & $\begin{array}{l}\text { In/outpatient (breaking } \\
\text { bad news). }\end{array}$ & Outpatient \\
\hline \multicolumn{8}{|l|}{ Intervention } \\
\hline \multirow[t]{2}{*}{$\begin{array}{l}\mathrm{TG} \text {, training group } \\
\mathrm{CG} \text {, control group }\end{array}$} & $\begin{array}{l}\text { TG }(n=10) \text { : oncologists } \\
\text { received a 1-day } \\
\text { workshop, } \\
\text { incorporating } \\
\text { presentation of } \\
\text { different specific } \\
\text { doctor behaviours, a } \\
\text { video model of ideal } \\
\text { behaviour, feedback in } \\
\text { role-playing exercises } \\
\text { and provision of } \\
\text { individualised } \\
\text { feedback on two } \\
\text { audiotaped real patient } \\
\text { informed consent } \\
\text { consultations. Group } \\
\text { size: four to six } \\
\text { participants. }\end{array}$ & $\begin{array}{l}\text { TG }(n=57) \text { nurses } \\
\text { received } 105 \mathrm{~h}(30 \mathrm{~h} \\
\text { theoretical } \\
\text { information }+75 \mathrm{~h} \text { of } \\
\text { role-playing exercises) } \\
\text { training to decrease } \\
\text { professional stress } \\
\text { levels, to improve } \\
\text { attitudes and } \\
\text { communication skills. } \\
\text { Training was given } \\
\text { during three } \\
\text { consecutive months. } \\
\text { Each month five } \\
\text { consecutive days. } \\
\text { Topics were } \\
\text { approached according } \\
\text { to increased } \\
\text { complexity. Groups } \\
\text { consisted of max. } 10 \\
\text { participants. }\end{array}$ & $\begin{array}{l}\text { TG }(n=29) \text { : basic } \\
\text { training and } \\
\text { consolidation } \\
\text { workshop. The 19-h } \\
\text { basic programme } \\
\text { consisting of two } 8-\mathrm{h} \\
\text { sessions and one 3-h } \\
\text { session. It included a } \\
\text { 2-h plenary session } \\
\text { focussing on } \\
\text { theoretical } \\
\text { information and } 17 \mathrm{~h} \\
\text { of small-group session } \\
\text { (max six participants) } \\
\text { practising skills in } \\
\text { role-play with } \\
\text { immediate feedback. } \\
\text { The consolidation } \\
\text { programme consisted } \\
\text { of six 3-h workshops } \\
\text { during } 3 \text { months. }\end{array}$ & $\begin{array}{l}\text { TG }(n=21) \text { : a } \\
\text { computer-assisted } \\
\text { instruction programme } \\
\text { consisting of four } \\
\text { modules: basic } \\
\text { communication skills; } \\
\text { breaking bad news; } \\
\text { effectively providing } \\
\text { information and how } \\
\text { to deal with patient's } \\
\text { emotions. } \\
\text { Communication } \\
\text { theory is also } \\
\text { presented, as are } \\
\text { multiple-choice } \\
\text { practice questions } \\
\text { about the video, with } \\
\text { immediate feedback. } \\
\text { Each module can be } \\
\text { completed within an } \\
\text { hour. }\end{array}$ & $\begin{array}{l}\text { TG }(n=28) \text { : nurses } \\
\text { received } 18 \mathrm{~h} \text { of } \\
\text { training. Training } \\
\text { focused on learning } \\
\text { facilitating skills and } \\
\text { consisted of } \\
\text { theoretical education, } \\
\text { discussion of } \\
\text { homework } \\
\text { assignment, } \\
\text { instruction regarding } \\
\text { skill, demonstration of } \\
\text { the skills and feedback } \\
\text { in role-playing } \\
\text { sessions. Training was } \\
\text { given for } 6 \text { days in } \\
\text { periods of } 3 \mathrm{~h} \text { and a } \\
\text { follow-up meeting } \\
\text { after } 2 \text { months. Group } \\
\text { size: } 10-15 \\
\text { participants. }\end{array}$ & $\begin{array}{l}\text { TG }(n=29) \text { : basic } \\
\text { training and } \\
\text { consolidation } \\
\text { workshop. The } 19 \mathrm{~h} \\
\text { basic programme } \\
\text { consisting of two } 8 \text {-h } \\
\text { sessions and one 3-h } \\
\text { session. It included a } \\
\text { 2-h plenary session } \\
\text { focussing on } \\
\text { theoretical } \\
\text { information and } 17 \mathrm{~h} \\
\text { of small-group session } \\
\text { practising skills in } \\
\text { role-play with } \\
\text { immediate feedback. } \\
\text { The consolidation } \\
\text { programme consisted } \\
\text { of six 3-h workshops } \\
\text { during 3 months. }\end{array}$ & $\begin{array}{l}\text { TG }(n=48) \text { : oncologists } \\
\text { received a 3-day } \\
\text { course, which was } \\
\text { learner centred, } \\
\text { incorporating } \\
\text { cognitive, experiential } \\
\text { and behavioural } \\
\text { components. Small } \\
\text { groups (three to five). } \\
\text { Role-playing with } \\
\text { patient simulators, } \\
\text { followed by video } \\
\text { review and group } \\
\text { discussion }\end{array}$ \\
\hline & No CG. & $\mathrm{CG}(n=58)$ : no training. & $\begin{array}{l}\text { CG }(n=33) \text { : basic } \\
\text { training without } \\
\text { consolidation } \\
\text { workshop. }\end{array}$ & No CG. & $\mathrm{CG}(n=23)$ : no training. & $\begin{array}{l}\mathrm{CG}(n=30) \text { : basic } \\
\text { training and no } \\
\text { consolidation } \\
\text { workshop. }\end{array}$ & CG $(n=45)$ : no training \\
\hline \multicolumn{8}{|l|}{ Measurement } \\
\hline $\begin{array}{c}\text { Observational } \\
\text { instrument }\end{array}$ & $\begin{array}{l}\text { Coding of audiotaped } \\
\text { consultations based on } \\
\text { a typology for ethical } \\
\text { communication within } \\
\text { four categories ( } 57 \\
\text { items); three } \\
\text { interviews at each } \\
\text { assessment point, two }\end{array}$ & $\begin{array}{l}\text { Cancer Research } \\
\text { Campaign In terview } \\
\text { Rating Manual } \\
\text { (CRCIRM) to rate } \\
\text { audiotaped interviews; } \\
\text { one interview at each } \\
\text { assessment point, } \\
\text { three assessment }\end{array}$ & $\begin{array}{l}\text { Cancer Research } \\
\text { Campaign Interview } \\
\text { Rating Manual to rate } \\
\text { audiotaped interviews; } \\
\text { one interview at each } \\
\text { assessment point, two } \\
\text { assessment points in } \\
\text { time. }\end{array}$ & $\begin{array}{l}\text { Communication Rating } \\
\text { System to rate } \\
\text { videotaped interviews; } \\
2-5 \text { interviews at each } \\
\text { assessment point, } \\
\text { three assessment } \\
\text { points in time. }\end{array}$ & $\begin{array}{l}\text { Roter Interaction } \\
\text { Analysis System } \\
\text { (RIAS) to rate } \\
\text { videotaped interviews; } \\
\text { one to six interviews } \\
\text { at each assessment } \\
\text { point, two assessment } \\
\text { points in time. }\end{array}$ & $\begin{array}{l}\text { Cancer Research } \\
\text { Campaign Interview } \\
\text { Rating Manual to rate } \\
\text { audiotaped interviews; } \\
\text { one interview at each } \\
\text { assessment point, two } \\
\text { assessment points in } \\
\text { time. }\end{array}$ & $\begin{array}{l}\text { Medical Interaction } \\
\text { Process System to rate } \\
\text { videotaped interviews; } \\
\text { two interviews at each } \\
\text { assessment point, two } \\
\text { assessment points in } \\
\text { time. }\end{array}$ \\
\hline
\end{tabular}




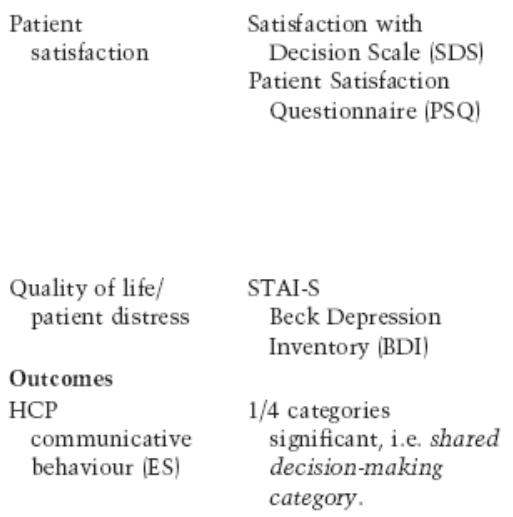

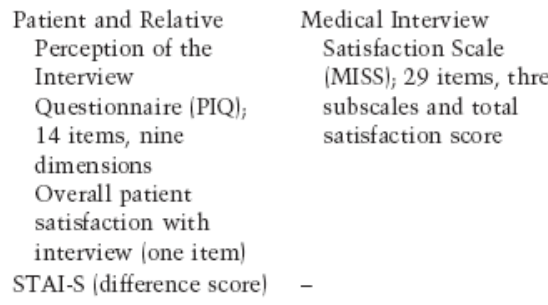
PPIQ significant, i.e assessment of concerms. No effects on the mean PQ score for both patien and relative. Overall satisfaction with interview lon item/ impro

No training effects on STAI-S
1/9 dimensions on the

\section{No training effects on}

Adapted Patient
Satisfaction
Questionnaire (PSQC);
seven items
Questionnaire (PPIQ) 14 items, nine

Overall patien

satisfaction with

interview fone item

EORTC QLQ-C30

STAI-S (difference score)

\section{No training effects on}

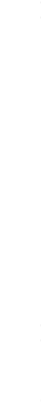
the MISS

\section{No training effects on} the adapted PSQC

QLQ-C30 any of the 37 changes in the ratio of

affective

communication.

\begin{tabular}{|c|c|}
\hline $\begin{array}{l}\text { 4/22 measured } \\
\text { behaviour were } \\
\text { significant, i.e. } \\
\text { acknowledgement } \\
\text { empathic statement; } \\
\text { educated guesses; } \\
\text { negotiation. }\end{array}$ & $\begin{array}{l}\text { Significant improvement } \\
\text { for: empathy; } \\
\text { appropriate responses } \\
\text { to patient cues; } \\
\text { psychosocial probing; } \\
\text { use of open questions }\end{array}$ \\
\hline $1 / 9$ dimensions on the & \\
\hline $\begin{array}{l}\text { PPIQ significant, i.e. } \\
\text { assessment of the }\end{array}$ & effect on the PSCQ \\
\hline $\begin{array}{l}\text { patient's } \\
\text { understanding of the }\end{array}$ & \\
\hline $\begin{array}{l}\text { disease. No effect on } \\
\text { the mean PPIQ score }\end{array}$ & \\
\hline nor overall patient & \\
\hline $\begin{array}{l}\text { satisfaction with } \\
\text { interview (one item). }\end{array}$ & \\
\hline No training effects on & - \\
\hline $\begin{array}{l}\text { the SIAI-S } \\
\text { MANOVA }\end{array}$ & ANCOVA \\
\hline
\end{tabular}
MANOV
Patient Satisfaction with Communication

Questionnaire (PSCQ) overall satisfactio score $-$

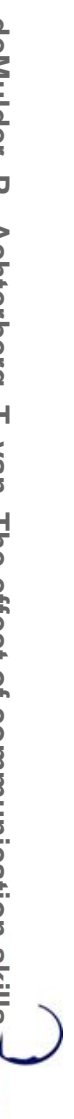


Uitterhoeve, R., Bensing, J., Grol, R., deMulder, P., Achterberg, T. van. The effect of communication skills 7 training on patient outcomes in cancer care: a systemtatic review of the literature. European Journal of Care: 2009

Figure 1. Forest plot of outcomes of training on HCP behaviour expressed as SMD. HCP, healthcare professional; SMD, standardisedmean differences.

\begin{tabular}{|c|c|c|c|c|c|c|c|c|c|}
\hline \multirow{2}{*}{\begin{tabular}{|l} 
Outcome \\
study
\end{tabular}} & \multicolumn{3}{|c|}{ Training } & \multicolumn{3}{|c|}{ Control } & \multirow[t]{2}{*}{$\begin{array}{c}\text { SMD (random) } \\
95 \% \mathrm{Cl} \\
\end{array}$} & \multicolumn{2}{|c|}{$\begin{array}{c}\text { SMD (random) } \\
95 \% \mathrm{Cl}\end{array}$} \\
\hline & Mean & SD & Total & Mean & SD & Total & & & \\
\hline Razavi et al. 2003 & 0.27 & 0.52 & 28 & 0.13 & 0.31 & 30 & $0.33[-0.19,0.84]$ & - & \\
\hline Delvaux et al. 2004 & 3.85 & 4.45 & 53 & 1.1 & 2.7 & 54 & $0.74[0.35,1.14]$ & & \\
\hline Educated guesses a & ollow-u & & & & & & & & \\
\hline Delvaux et al. 2004 & 2.56 & 2.72 & 51 & 1.5 & 2.19 & 54 & $0.43[0.04,0.81]$ & & \\
\hline Acknowledgement & & & & & & & & & \\
\hline Razavi et al. 2003 & 28.25 & 11.72 & 28 & 26.36 & 9.22 & 30 & $0.18[-0.34,0.69]$ & & \\
\hline Empathic statement & & & & & & & & & \\
\hline Razavi et al. 2003 & 0.49 & 1.02 & 28 & 0.11 & 0.26 & 30 & $0.51[-0.01,1.04]$ & & \\
\hline Negotiations & & & & & & & & & \\
\hline Razavi et al. 2003 & 1.25 & 1.18 & 28 & 0.64 & 0.8 & 30 & $0.60[0.07,1.13]$ & & \\
\hline Shared decision-ma & $\mathrm{ng}^{1}$ & & & & & & & & \\
\hline Brown et al. 2007 & 5.8 & 2.12 & 31 & 4.8 & 2.04 & 59 & $0.48[0.04,0.92]$ & & \\
\hline${ }^{1} \mathrm{SMD}$ is based on pre-te & ost-test & difference & & & & & & $\begin{array}{cc}-1 & -0.5 \\
\text { Favours control } & 0\end{array}$ & $\begin{array}{cc}0.5 & 1 \\
\text { Favours training }\end{array}$ \\
\hline
\end{tabular}

Figure 2. Forest plot of outcomes of training on HCP behaviour expressed as RR. HCP, healthcare professional; RR, relative risk.

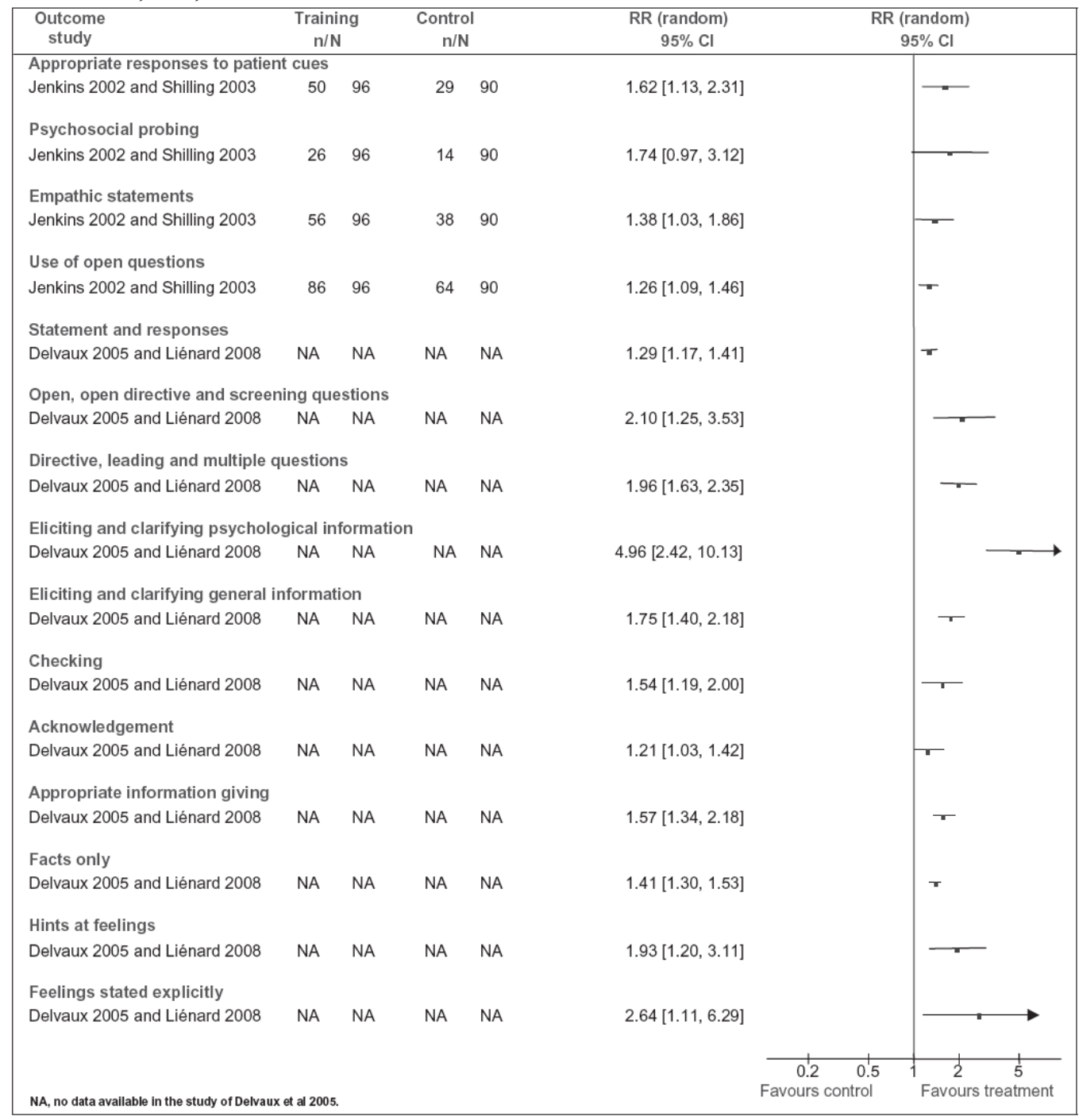


Uitterhoeve, R., Bensing, J., Grol, R., deMulder, P., Achterberg, T. van. The effect of communication skills 7 training on patient outcomes in cancer care: a systemtatic review of the literature. European Journal of ean Care: 2009

Figure 3. Forest plot of outcomes of training on patient satisfaction expressed as SMD. PPIQ, Patients' Perception of the Interview Questionnaire; SMD, standardised mean differences.

\begin{tabular}{|c|c|c|c|c|c|c|c|c|c|}
\hline \multirow{2}{*}{\begin{tabular}{|l} 
Outcome \\
study
\end{tabular}} & \multicolumn{3}{|c|}{ Treatment } & \multicolumn{3}{|c|}{ Control } & \multirow{2}{*}{$\begin{array}{c}\text { SMD (random) } \\
95 \% \mathrm{Cl}\end{array}$} & \multirow{2}{*}{\multicolumn{2}{|c|}{$\begin{array}{c}\text { SMD (random) } \\
95 \% \mathrm{Cl}\end{array}$}} \\
\hline & Mean & SD & Total & Mean & SD & Total & & & \\
\hline \multicolumn{10}{|c|}{ Satisfaction with clarification of preoccupations } \\
\hline Delvaux et al. 2004 & 3.06 & 1.01 & 54 & 2.96 & 1.05 & 57 & $0.10[-0.28,0.47]$ & & \\
\hline \multicolumn{10}{|c|}{ Satisfaction with information and support } \\
\hline Delvaux et al. 2004 & 2.75 & 0.99 & 54 & 2.68 & 0.94 & 57 & $0.07[-0.30,0.44]$ & & \\
\hline \multicolumn{10}{|c|}{ PPIQ - assessment of patients' understanding of the disease } \\
\hline Razavi et al. 2003 & 3.93 & 0.26 & 29 & 3.8 & 0.41 & 30 & $0.37[-0.14,0.89]$ & & \\
\hline \multicolumn{10}{|c|}{ Satisfaction with clarification of preoccupation at follow-up (6 months) } \\
\hline Delvaux et al. 2004 & 3.24 & 0.99 & 52 & 2.8 & 0.98 & 58 & $0.44[0.06,0.82]$ & & \\
\hline \multicolumn{10}{|c|}{ Satisfaction with information and support at follow-up (6 months) } \\
\hline Delvaux et al. 2004 & 2.86 & 0.9 & 52 & 2.55 & 0.89 & 58 & $0.34[-0.03,0.72]$ & & \\
\hline \multicolumn{10}{|c|}{ PPIQ - assessment of concerns } \\
\hline \multirow[t]{2}{*}{ Delvaux 2005} & 3.63 & 0.61 & 27 & 3.07 & 0.93 & 29 & $0.70[0.16,1.24]$ & & \\
\hline & & & & & & & & $\begin{array}{cc}-1 & -0.5 \\
\text { Favours control }\end{array}$ & \begin{tabular}{|ccc}
0 & 0.5 & 1 \\
& Favours treatment
\end{tabular} \\
\hline
\end{tabular}

Table 5. Clinical significance of HCP communicative behaviour expressed as RR

\begin{tabular}{lll}
\hline HCP communicative behaviour & RR $(95 \%$ CI) & NNT (95\% CI) \\
\hline Appropriate responses to patient cues (Jenkins \& Fallowfield 2002; Shilling et al. 2003) & $1.62(1.13,2.31)$ & $5(3,16)$ \\
Psychosocial probing (Jenkins \& Fallowfield 2002; Shilling et al. 2003) & $1.74(0.97,3.12)$ & $9(4, \infty)$ \\
Empathic statements (Jenkins \& Fallowfield 2002; Shilling et al. 2003) & $1.38(1.03,1.86)$ & $6(3,55)$ \\
Use of open questions (Jenkins \& Fallowfield 2002; Shilling et al. 2003) & $1.26(1.09,1.46)$ & $5(3,13)$ \\
\hline
\end{tabular}

HCP, healthcare professional; NNT, number needed to treat; RR, relative risk. 